\title{
Human migration and occupation of Eurasia
}

\author{
Dept. of Archaeology, University of Sheffield, Sheffield S1 4ET, U.K.Email: R.Dennell@sheffield.ac.uk
}

The main current benefit of collaboration between Quaternary scientists and palaeoanthropologists (especially palaeolithic archaeologists) lies in providing a unique perspective on how human populations respond to longterm climate change. Eurasia has a superlative record of climatic changes over the last two million years, and an archaeological record that is regionally variable in quality, but which is drawn from a wide range of environmental and chronological contexts. At a continental scale, the integration of these records allows the past 2 Ma to be divided into six major themes of how hominins (our remote ancestors) and our own species responded to climatic changes at Milankovitch and subMilankovitch scales. These themes are the initial hominin colonisation of Asia after $2 \mathrm{Ma}$; the dispersal of hominins into Europe in the Early Pleistocene and its eventual permanent colonisation in the Middle Pleistocene; the expansion of Acheulean, bifacial assemblages from the Levant to western Europe and India after $600 \mathrm{ka}$; the responses of hominin populations to Milankovitch-length climatic changes during the Middle Pleistocene; the expansion of modern humans after 100 ka across Eurasia and later into Australasia and the Americas; and the recolonisation at millennial scales of abandoned areas of Eurasia at the end of last ice age. As the quality of Quaternary and archaeological information improves, these responses of past human populations to climatic change will be documented at a level of detail unimaginable a few decades ago. Cumulatively, this type of collaboration provides a unique perspective on the consequences of large-scale climatic change upon human populations that is particularly relevant to current concerns of climate change

\section{Introduction}

The main theme of the last two million years of human prehistory in Eurasia is one of population movements resulting from climatic change. When conditions were favourable, humans (and their predecessors) dispersed into and often colonised new areas or re-colonised ones previously abandoned. As conditions deteriorated, the limits of human settlement contracted as populations retreated southwards; some areas were abandoned, and doubtless many populations became extinct. In Europe, the main climatic variables affecting hominin populations were winter temperatures and rain/snowfall: as ice sheets expanded and retreated, hominins followed suit and often most of northern Europe was abandoned. In Asia, where ice sheets were never as extensive, the main climatic variable determining where hominins could live was probably rainfall. This factor was particularly important in areas that are dependent upon rain from the Mediterranean, notably inland Southwest Asia and Central Asia; and also North China that lies at the northern limit of the East Asian summer monsoon. Figure 1 provides a useful summary model of the consequences of glacial and interglacial climates on hominin populations during the Pleistocene.

Pleistocene climatic changes in Eurasia are now known in great detail, thanks primarily to the marine isotope records of the North Atlantic, Mediterranean, Indian Ocean, South China Sea, and West Pacific. There are also some excellent terrestrial records from Asia (summarised in Dennell in press), notably the 22 Ma loess and palaeosol record of the Chinese Loess Plateau, a 10 Ma record from Lake Baikal in Siberia, and the 2.5 Ma loess and palaeosol record of Tajikistan, Central Asia. Other useful but partial terrestrial climatic sequences come from South China, India, the Arabian Peninsular and the Levant. The record of Pleistocene climate in the European peninsula is of course extremely well documented. As a result of these records, we can now begin to model and investigate human prehistory in Eurasia in terms of human responses to climatic shifts over Milankovitch cycles, as well as millennial and sub-millennial lengths. This signifies a major change (first developed in Europe in the 1980's; see e.g., Gamble, 1986) from using Pleistocene climatic sequences primarily as a means of dating fossils and stone tools to using them to model how hominin populations responded to different climatic and environmental conditions (see e.g., Roebroeks ,2001). With the information now available, palaeolithic archaeologists are uniquely equipped to study long term human responses to climate change.

Eurasian palaeoanthropology (including its Palaeolithic record) is largely about six major processes of migration into and colonisa-
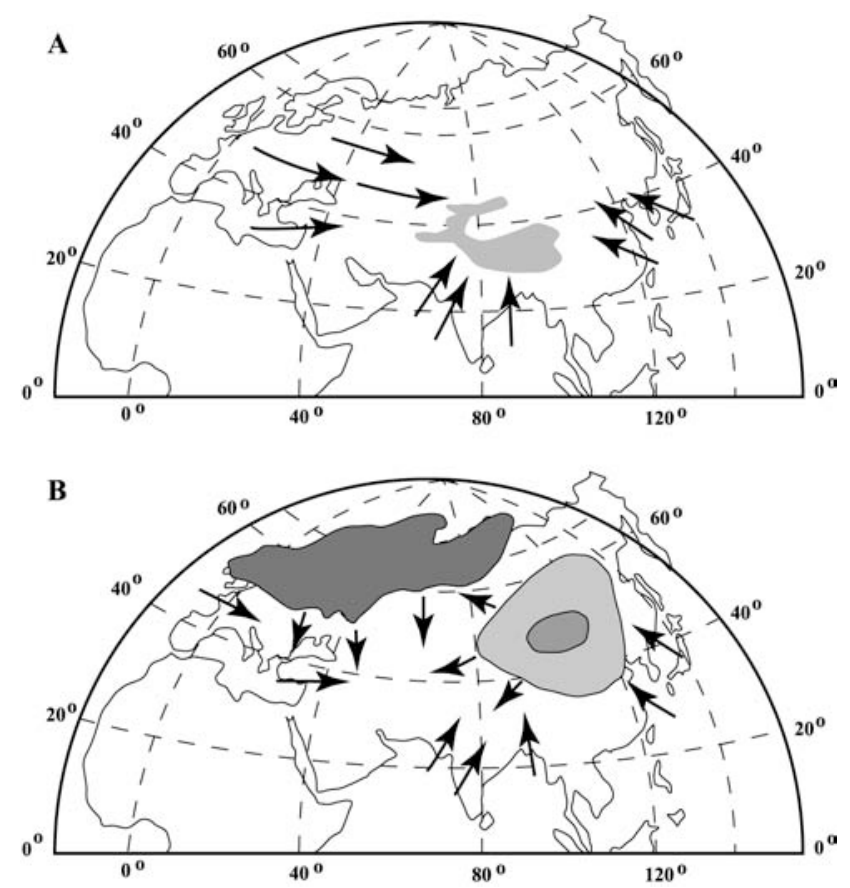

Figure 1 Dodonov and Baiguzina's model of Pleistocene glacial and interglacial climate. 
tion of new areas, and their opposite conditions of abandonment and isolation. In favourable periods, the outcomes were the expansion of populations, the colonisation of new areas, and the integration of adjoining populations; in unfavourable (cold, arid) periods, the consequences were often the southward retreat of some populations, the abandonment of colonised areas, and the isolation or fragmentation of populations (see e.g., Dennell, 2007; Petraglia and Dennell, 2007). Consequently, many Eurasian regional Palaeolithic sequences show numerous discontinuities in their settlement records (Dennell 2003, 2004). For the most part, hominins danced to the rhythms of Pleistocene climatic change. However, their responses were not unchanging like those of other animals, because hominins evolved, and their behavioural capabilities developed. Hominins 0.5 Ma were undoubtedly more competent than their counterparts a million years earlier, and were even more competent at 35,000 ka and $15,000 \mathrm{ka}$. Thus conditions that might have been insurmountable for hominins at $500 \mathrm{ka}$ were coped with $50 \mathrm{ka}$ because of improvements in hunting, gathering and food-processing techniques, clothing, shelter, the use and control of fire, the ability of hominins to procure raw materials over great distances, improvements in their communication skills (especially language), as well as in their cognitive awareness of their social landscapes. Thus the Pleistocene hominin record of Eurasia can be seen as a game between the vicissitudes of Pleistocene climatic change on the one hand, and on the other, a hominin that gradually (or at times, suddenly) developed better means of coping with adverse climatic and environmental changes.

\section{Six major processes of Pleistocene migration, dispersal and colonisation in Eurasia}

The most important and fruitful interactions between Quaternary studies and palaeoanthropology continue to be in six areas of research - two each in the Early and Middle Pleistocene, and three in the Upper Pleistocene.

\section{1) The expansion of hominins (particularly Homo) from Africa.}

The earliest widely accepted evidence for hominins outside Africa is from Dmanisi, Georgia, where the remains of hominins and stone tools ca. 1.75 Ma have been found. These hominins were a short, small-brained and very primitive form of Homo erectus. Slightly younger evidence of $H$. erectus has been found in Java, ca. 1.6 Ma, and probably in the Nihewan Basin, North China, where the oldest stone tools are ca. $1.66 \mathrm{Ma}$, although so far associated hominin remains have not been found. Two major issues of ongoing debate are when hominins first dispersed out of Africa, and whether $H$. erectus was the first and only hominin to leave in the Late Pliocene. On current evidence, it is possible that $H$. erectus originated in Southwest Asia from a population that left Africa before 2 $\mathrm{Ma}$, and then dispersed back into East Africa as well as eastwards to Java and China. Other related issues are how Early Pleistocene hominins responded to the " $41 \mathrm{ka"} \mathrm{world} \mathrm{of} \mathrm{minor} \mathrm{glacial} \mathrm{and} \mathrm{inter-}$ glacial episodes in continental Asia, and whether the few observations we have of Early Pleistocene hominins in Asia are derived from core areas of settlement (as is likely in the Levant, Georgia and Java), or areas that were inhabited only when conditions were favourable, as may have been the case in North China.

\section{2) The earliest colonisation of Europe}

The earliest incontrovertible and well-dated evidence for hominins in Europe is from Atapuerca, Spain, and is ca. 1.2 Ma. More abundant and slightly younger evidence ca. 1.0 Ma comes from the Orce Basin, Spain and Ceprano, Italy, and particularly from Atapuerca after $0.8 \mathrm{Ma}$. These hominins are probably descended from those at Dmanisi, and are usually classified as $H$. antecessor. These may have evolved into $H$. heidelbergensis, which is the main type of hominin evidenced in Europe after $600 \mathrm{ka}$. Ongoing research concerns are to model when and how often hominins dispersed westwards across southern Europe; when they first moved into northern Europe (where the earliest evidence is currently ca. $600 \mathrm{ka}$; see Parfitt et al., 2005); where the core populations were in MIS 16 (620-650 ka), MIS 14 (524-565) and MIS 12 (424-478 ka); and whether the hominin fossil and archaeological record from Europe indicates continual residence, or episodic dispersals and local extinctions.

\section{3) The expansion of the Acheulean}

The Acheulean bifacial hand axe is of the most distinctive and enduring features of the Early Palaeolithic record in Africa, Europe and Asia. The earliest examples are East African ca. 1.6 Ma, and the earliest in Eurasia are from 'Ubeidiya, Israel, ca. 1.4 Ma. They do not appear to have expanded out of the African and Jordan Rift Valley until after $800 \mathrm{ka}$. However, by ca. $500 \mathrm{ka}$, they are found 2,500 miles $(4,000 \mathrm{~km})$ to the east in India, and the same distance to the west in Europe. It remains uncertain whether the expansion of the Acheulean resulted from the migration of hominins, the diffusion of knowledge about the manufacture and use of a multi-purpose tool, or was part of the diffusion of a larger behavioural package that included the ability to hunt large animals and perhaps also control fire. It is also unclear whether the bulk of this expansion occurred in MIS 11 (362-423 ka), which appears from the Lake Baikal records to have been exceptionally long and mild in Central Asia (Prokopenko et al., 2002).

\section{4) The mid-latitude, Middle Pleistocene record: colonisation and abandonment}

The shift to the 100-ka world of the Middle Pleistocene after $600 \mathrm{ka}$ (Mudelsee and Schultz 1997) had momentous consequences on hominin populations between $40-50^{\circ} \mathrm{N}$. Evidence across Eurasia from Britain (Stringer, 2006), Central Asia (Ranov and Dodonov, 1995) and North China (Zhou et al., 2000) all indicates that hominins abandoned these regions for up to $80 \%$ of the last $500-600 \mathrm{ka}$. This pattern is illustrated by the palaeoclimatic and Palaeolithic records from Tajikistan, Central Asia (Figure 2), which clearly shows that hominins were present only during interglacials. In Britain, the main reason why hominins retreated was because of the repeated advances of ice and low temperatures; in Central Asia and North China, reduced rainfall and harsher winters were probably the most important factors that led to the abandonment of these areas.

\section{5) The early to mid-Upper Pleistocene: the expansion of modern humans (Out of Africa 2)}

The main evidence for anatomically modern forms of $\mathrm{H}$. sapiens dates from ca. 160-190 ka in East Africa, and ca. 130-125 ka in Southwest Asia. On current evidence, modern humans dispersed from East Africa (possibly following a coastal route; see e.g., Stringer, 2000) or the Levant after the last interglacial (MIS 5e) and colonised the Australian landmass ca. 55-60 ka, which they could only have done so by using boats with paddles or sails. Europe was colonised by modern humans much later, and probably between 35-30 ka. Here, the expansion of modern humans is intricately interwoven with the extinction of Neanderthals during MIS 3 (see e.g., Andel and Davies, 2003), and debate continues over the role of climatic instability, competition, and/or technological and cognitive differences between the two populations. In Asia, the expansion of modern humans across southern Asia was accompanied by an eastward expansion of Neanderthals across Central Asia in MIS 4 and 3 (Howell, 1999). The events and environmental circumstances that led to the extinction of the latter are unclear, as is the date of the last Asian Neanderthals. 


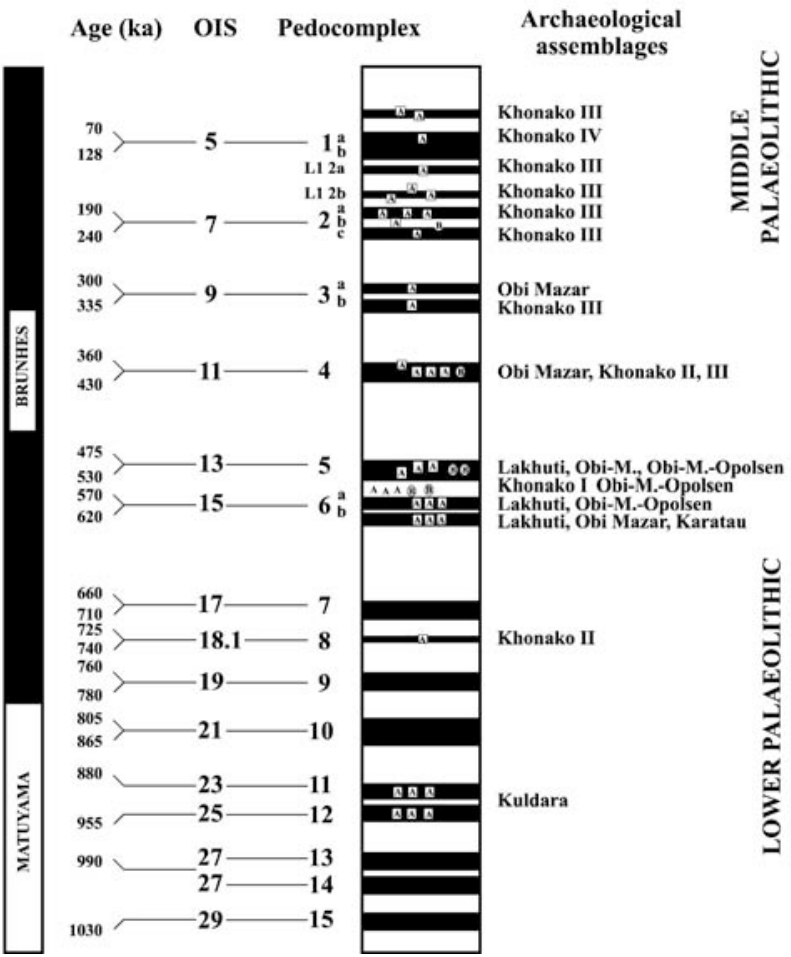

Figure 2 Age and stratigraphic context of Palaeolithic sites in Tajikistan. (Sources: Dodonov 2002; Tables 9 and 14; Ranov and Dodonov 2003; Figure 10). Black bars denote interglacial pedocomplexes (palaeosols); intervening white parts denote glacial loess. As is evident, this region was occupied only during interglacials.

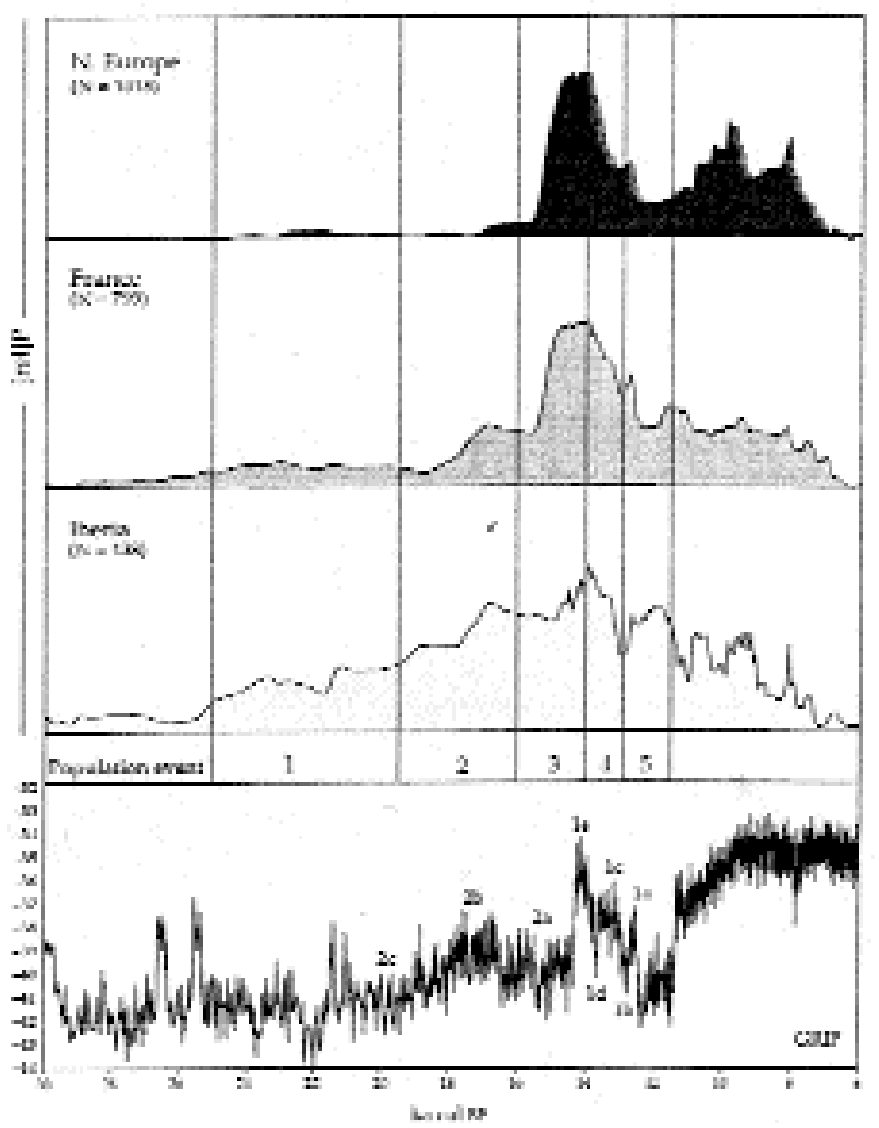

Figure 3 The late glacial recolonisation of $N$. Europe.
6) Late glacial expansion of human populations: colonisation and re-colonisation

Studies of a substantial part of the Eurasian late Palaeolithic after the last glacial maximum (ca. 21-15 ka) are primarily about the re-colonisation of areas previously too cold and/or ice-bound to inhabit. The re-colonisation of northern Europe is now documented in enormous detail (see Figure 3), and can be plotted with a resolution of only a few centuries. The re-colonisation of areas in Asia that were abandoned in the coldest parts of MIS 2 are known only sketchily, notably the Tibetan Plateau (first colonised 30-40 ka, almost certainly abandoned in MIS 2 and then re-colonised by $12 \mathrm{ka}$; see Madsen et al., 2001; Yuan et al., 2007) and Siberia. The latter area was first colonised in MIS 3, abandoned, and then swiftly recolonised by groups that possessed the necessary clothing, hunting, fishing and trapping technologies, abilities to move across snow and endure extreme cold (Goebel, 1999). Some of these groups probably reached North America near the end of the Pleistocene across Beringia, the subcontinent now submerged by the Bering Straits (see e.g., Dalton, 2003); alternatively, some groups from western Europe may have reached the eastern coast of North America across the North Atlantic pack ice (see e.g., Bradley and Stanford, 2004).

\section{Discussion}

The combination of Quaternary and Palaeolithic research provides immense opportunities for obtaining a unique perspective on human responses to climate change over long-term timescales at a continental to regional scale. In some case-such as Middle Pleistocene Britain and Tajikistan - it is possible to model these in detail across glacial and interglacial cycles, and to show the climatic conditions that were conducive or intolerable for sustained human occupation. In exceptionally well-documented situations, such as the late glacial records of northern Europe, human responses to climatic changes over only a few centuries can be analysed. What we need are more well-dated archaeological and fossil hominins with climatic and environmental contexts, and more Quaternary data that can estimate variables such as rainfall, snowfall, and temperatures as with MIS 2, 3 and $5 e$, and perhaps 6 and 11 .

\section{References}

Andel, T. van, and Davies, W., 2003, eds, Neanderthals and modern humans in the European landscape during the last glaciation: Cambridge, McDonald Institute Monograph.

Bradley, B., and Stanford, D., 2004, The north Atlantic ice-edge corridor: a possible Palaeolithic route to the New World: World Archaeology, v. 36, no. 4, pp. 459-478.

Dalton, R., 2003, The coast road: Nature, v. 422, pp. 10-12.

Dennell, R.W., 2003, Dispersal and colonisation, long and short chronologies: how continuous is the Early Pleistocene record for hominids outside East Africa?: Journal of Human Evolution, v. 45, pp. 421-440.

Dennell, R.W., 2004, Hominid dispersals and Asian biogeography during the Lower and Early Middle Pleistocene, ca. 2.0-0.5 Mya: Asian Perspectives, v. 43, no. 2, pp. 205-226.

Dennell, R.W., 2007, Archaeological Archives from Asia, 2.7 MYR 300,000 years ago, in Elias, S.A., ed, Elsevier Encyclopedia of Quaternary Science: Elsevier B.V., pp. 73-89.

Dennell, R.W., in press, The Palaeolithic Settlement of Asia: Cambridge, Cambridge University Press.

Dodonov, A.E., 2002, Quaternary of Middle Asia: Stratigraphy, Correlation and Paleogeography: Moscow, Geos. (In Russian).

Dodonov, A.E., and Baiguzina, L.L., 1995, Loess stratigraphy of Central Asia: palaeoclimatic and palaeoenvironmental aspects: Quaternary Science Reviews, v. 14, pp. 707-720.

Gamble, C., 1986, The Palaeolithic Settlement of Europe: Cambridge, Cambridge University Press.

Gamble, C., Davies, W., Pettitt, P., Hazelwood, L., and Richards, M., 2005, The archaeological and genetic foundations of the European population 
during the Late Glacial: implications for 'Agricultural Thinking': Cambridge Archaeological Journal, v. 15, pp. 193-223.

Goebel, T., 1999, Pleistocene human colonization of Siberia and peopling of the Americas: an ecological approach: Evolutionary Anthropology 1998, v. 6, pp. 208-227.

Howell, F.C., 1999, Paleo-demes, species clades, and extinctions in the Pleistocene hominin record: Journal of Anthropological Research, v. 55, pp. 191-243.

Madsen, D.B., Ma Haizhou, Brantingham, P.J., Gao Xing, Rhode, D., Zhang Haiying, and Olsen, J.W., 2006, The Late Upper Paleolithic occupation of the northern Tibetan Plateau margin: Journal of Archaeological Science, v. 33, pp. 1433-1444.

Mudelsee, M., and Schulz, M., 1997, The Mid-Pleistocene climate transition: onset of 100 ka cycle lags ice volume build-up by $280 \mathrm{ka}$ : Earth and Planetary Science Letters, v. 151, pp. 117-123.

Parfitt, S.A., Barendregt, R.W., Breda, M., Candy, I., Collins, M.J., Coope, G.R., Durbridge, P., Field, M.H., Lee, J.R., Lister, A.M., Mutch, R., Penkman, K.E.H., Preece, R.C., Rose, J., Stringer, C.B., Symmons, R., Whittaker, J.E., Wymer, J.J., and Stuart, A.J., 2005, The earliest record of human activity in northern Europe: Nature, v. 438, pp. 1008-1012.

Petraglia, M.D., and Dennell, R.W., 2007, The Archaeology of Global Expansion 300,000-8000 years ago: Asia, in Elias, S.A., ed, Elsevier Encyclopedia of Quaternary Science: Elsevier, pp. 107-118.

Prokopenko, A.A., Williams, D.F., Kuzmin, M.I., Karabanov, E.B., Khursevich, G.K., and Peck, J.A., 2002, Muted climate variations in continental Siberia during the mid-Pleistocene epoch: Nature, v. 418, pp. 65-68.

Ranov, V.A., and Dodonov, A.E., 2003, Small instruments of the Lower Palaeolithic site Kuldara and their geoarchaeological meaning, in Burdukiewicz, J.M., and Ronen, A., eds, Lower palaeolithic small tools in Europe and Asia: British Archaeological Reports (International Series), v. 1115, pp. 133-147.

Roebroeks, W., 2001, Hominid behaviour and the earliest occupation of Europe: an exploration: Journal of Human Evolution, v. 41, pp. 437-461.
Stringer, C.B., 2000, Coasting out of Africa: Nature, v. 405, pp. 24-25. Stringer, C.B., 2006, Homo Britannicus: the incredible story of human life in Britain: London, Penguin.

Yuan, Bao Yin, Huang Weiwen, and Zhang, D., 2007, New evidence for human occupation of the northern Tibetan Plateau, China during the Late Pleistocene: Chinese Science Bulletin, v. 52, no. 19, pp. 2675-2679.

Zhou, C., Liu, Z., Wang, Y., and Huang, Q., 2000, Climatic cycles investigated by sediment analysis in Peking Man's cave, Zhoukoudian, China: Journal of Archaeological Science, v. 27, pp. 101-109.

Robin Dennell's main research interest is the Palaeolithic and Pleistocene of Asia. From 1981 to 1999, he conducted extensive fieldwork in Pakistan as part of a wider interest in early human evolution and environmental change in Asia. After serving as Head of Department from 1999-2002, he was awarded a three-year British Academy Re search Professorship (2003-2006), to write "The Palaeolithic Settlement of Asia" (to be published by Cambridge University Press), which will be the first overview of the Asian Early Palaeolithic and Pleistocene before the last interglacial. He is currently investigating patterns of colonization and abandonment in Asia during the Pleistocene.

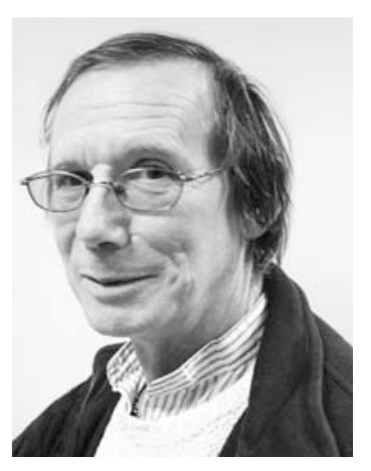

